\title{
'Eu tenho que me reeducar': discursos normativos e práticas alimentares relacionadas à perda de peso em mulheres de camadas populares
}

\section{'I ought to reeducate myself': normative discourses and eating practices related to weight loss in women of the popular strata}

\author{
Tatiana Coura Oliveira' \\ Dina Czeresnia \\ Eliane Portes Vargas ${ }^{3}$ \\ 1 Universidade Federal de Viçosa, Instituto de \\ Ciências Biológicas e da Saúde. Rio Paranaíba- \\ MG, Brasil. \\ ${ }^{2}$ Escola Nacional de Saúde Pública Sergio Arouca \\ - Fiocruz. Rio de Janeiro-RJ, Brasil. \\ ${ }^{3}$ Instituto Oswaldo Cruz - Fiocruz. Rio de \\ Janeiro-RJ, Brasil. \\ Correspondência / Correspondence \\ Tatiana Coura Oliveira \\ Instituto de Ciências Biológicas e da Saúde, \\ Universidade Federal de Viçosa, campus de \\ Rio Paranaíba. Rodovia MG-230 - Km 7, CEP \\ 38810-000. Rio Paranaíba, MG, Brasil. \\ E-mail: tatiana.coura@ufv.br
}

\section{Resumo}

Este artigo propõe uma reflexão sobre como os discursos normativos relacionados à alimentação e saúde são apropriados por mulheres que apresentam excesso de peso, considerando a centralidade destes discursos nas orientações e ações de educação e reeducação alimentar. As práticas educativas em alimentação estão historicamente assentadas na lógica do risco, que, por sua vez, rege o discurso do campo da saúde, o que inclui as abordagens e intervenções de controle da obesidade. Com base em uma pesquisa etnográfica realizada com mulheres de camadas populares atendidas em um centro de saúde do Rio de Janeiro, as reflexões aqui desenvolvidas problematizam a dificuldade de conectar informações pouco criteriosas a um processo de reflexão e de cuidado de si. A ideia de racionalidade de sujeitos autônomos informados sobre o "valor nutricional" dos alimentos ou do "risco de adoecimento" se traduz em orientações que apresentam resultados limitados. As noções de educação e reeducação alimentar, presentes nas narrativas das informantes, evidenciam um modelo que desconsidera aspectos que se ligam às condições materiais e à identidade sociocultural dos grupos, propondo mudanças de hábitos que não se sustentam no cotidiano das pessoas.

Palavras-chave: Práticas Alimentares Saudáveis. Educação Alimentar e Nutricional. Excesso de peso. 


\section{Abstract}

The current article is a reflection about how normative discourses related to eating and health are held by overweight women, by considering that these discourses focus on dietary education and reeducation guidelines and actions. Educational feeding practices are historically based on the logic of risk driving the discourse on health, which include obesity-control approaches and interventions. Based on an ethnographic research carried out with women of the popular strata treated at a healthcare center in Rio de Janeiro, the reflections problematize the difficulty of connecting little-detailed information to a reflective and selfcare process. The idea of rationality of autonomous subjects informed about the "nutritional value" of food or about the "risk of illness" is translated into guidelines that show limited results. The concepts of dietary education and reeducation found in the informants' narratives show a model that ignores aspects related to the material conditions and sociocultural identity of the groups, since it suggests habit changes that do not comply with the daily life of these individuals.

Keywords: Healthy Eating Practices. Dietary And Nutritional Education. Overweight.

\section{Introdução}

Este artigo propõe uma reflexão sobre como os discursos normativos relacionados à alimentação e saúde são apropriados por mulheres que apresentam excesso de peso, considerando a centralidade destes discursos nas orientações e ações educativas no campo da Nutrição. A educação alimentar constitui um marco conceitual no campo, bem como na prática do profissional nutricionista desde a metade do século passado, firmando-se como disciplina curricular já no primeiro curso de formação profissional promovido pelo Serviço de Alimentação da Previdência Social (SAPS, 1944). ${ }^{1-3}$ Contudo, entendemos que o conceito de educação nutricional promove uma compreensão reduzida das dimensões que se ligam ao comer, enquanto constructo social. ${ }^{4}$ Esta reflexão tem por pressuposto serem as práticas educativas em alimentação historicamente assentadas na lógica do risco, que, por sua vez, rege o discurso sobre a saúde, o que inclui as abordagens e intervenções de controle da obesidade. ${ }^{5,6}$

Nas últimas décadas, o incremento de trabalhos científicos publicados no campo da saúde apresentou forte articulação entre alimentação e controle de doenças, principalmente as crônicodegenerativas. ${ }^{7}$ Nesse cenário, a obesidade assumiu lugar de destaque, sendo apontada em estudos epidemiológicos como risco para agravos como hipertensão arterial, dislipidemias, diabetes tipo 
2, doença arterial coronariana, acidente vascular cerebral, osteoartrite e problemas respiratórios, entre outras questões. ${ }^{8}$ No âmbito da ciência da Nutrição, as publicações reproduziram os padrões da investigação biomédica com estudos marcados pela centralidade da doença, atribuindo maior ênfase aos aspectos nutricionais e aos fatores de risco relacionados a práticas alimentares, em detrimento às questões mais amplas ligadas à alimentação humana. ${ }^{9,10}$

Esses estudos não ficaram confinados ao espaço científico, disseminando-se em diferentes instâncias para o público em geral. Isso ocorreu no contexto da centralidade que a preocupação com a saúde assumiu no cotidiano das pessoas. ${ }^{11,12}$ É possível encontrar inúmeros programas televisivos e revistas semanais especializadas em questões relacionadas ao corpo, alimentação e saúde; além de espaços digitais como sites ou blogs, que reproduzem o discurso científico de saúde alimentar. ${ }^{13-15}$

Paradoxalmente, este incremento na produção e divulgação científica que se liga à temática se contrapõe ao avanço dos indicadores de sobrepeso e obesidade, que no Brasil, atingem quase $60 \%$ da população adulta. ${ }^{16}$ Este cenário permite o questionamento das abordagens normativas atreladas ao discurso da saúde, cujos limites têm se evidenciado. Apesar da complexidade e importância dos aspectos macroestruturais na determinação da epidemia global do excesso de peso, a natureza ambiental do problema é predominantemente estudada mediante conceitos mais restritos, que abordam a questão na perspectiva individual, como risco e estilo de vida.

Enquanto problema de saúde pública, o aumento global nos indicadores de excesso de peso levanta a necessidade de reflexões sobre questões mais amplas que se ligam às práticas alimentares em seu contexto micro e macrossocial, cujas transformações não se restringem à ampliação do acesso à informação nutricional ou orientação prescritiva. ${ }^{17} \mathrm{~A}$ ideia de racionalidade pautada na idealização de sujeitos autônomos e capazes de realizar 'boas escolhas' a partir de informações sobre "risco de adoecimento" ou "valor nutricional" se traduz em orientações normativas, apresentando resultados limitados. ${ }^{18}$ No âmbito da assistência à saúde, este pensamento reproduz ações que reduzem o excesso de peso a uma perspectiva conceitual de balanço energético positivo.

Considerando os aspectos assinalados e tendo por base uma pesquisa etnográfica realizada no Rio de Janeiro ${ }^{\mathrm{a}}$ com mulheres de camadas populares atendidas em um centro de saúde, as ponderações aqui desenvolvidas problematizam a dificuldade de conectar informações pouco criteriosas disseminadas a um processo de reflexão e de cuidado de si, a partir das seguintes questões norteadoras: como se apresentam as informações hoje disponíveis para a escolha alimentar? Que elementos concorrem nas opções realizadas no cotidiano? Como percebemos o caráter "educativo" do profissional da nutrição nesta seara?

a Tese apresentada ao Programa de Pós-graduação em Epidemiologia em Saúde Pública da Escola Nacional de Saúde Pública Sergio Arouca, na Fundação Oswaldo Cruz. Programa de Epidemiologia em Saúde Pública. 2016. 


\section{Método}

\section{Os caminhos da pesquisa: O TRABALHO DE CAMPO E OS SUJEITOS DA PESQUISA}

No fazer etnográfico, a teoria se conjuga à evidência empírica a partir de um processo reflexivo de aproximação entre pesquisador e o fenômeno que se pretende compreender. ${ }^{19} \mathrm{~A}$ reflexividade presente neste tipo de abordagem privilegia a investigação e sua relação de intersubjetividade com os grupos sociais. Ela se conforma pela atenção constante sobre o que e como ocorre, considerando que a observação empírica afeta o campo e a vida social, sendo impossível isolar a produção do conhecimento do sujeito que a produziu. Assim como a aproximação do pesquisador em relação ao fenômeno que se pretende compreender, tal processo só é possível a partir da compreensão de que a teoria é indissociável da prática. ${ }^{19,20}$

O estudo foi desenvolvido em um Centro de Saúde que atende os moradores de um conjunto de comunidades no território de Manguinhos/RJ. Tal escolha se deu por duas razões: (1) este Centro se constitui em uma referência de atendimento à saúde na comunidade; (2) razões de segurança relacionadas ao avanço da violência neste território mediante o agravamento da crise econômica e sociopolítica no país.

Tendo em vista a perspectiva teórico-metodológica do estudo, o trabalho de campo foi realizado entre os meses de setembro e novembro de 2015, considerando as seguintes etapas: (1) realização de observação dos atendimentos ambulatoriais de Nutrição, dos encontros de um grupo de apoio multidisciplinar a usuários do serviço que apresentavam excesso de peso e visitas domiciliares realizadas por uma agente de saúde no território e (2) entrevistas semiestruturadas com vinte e uma mulheres de camadas populares usuárias do serviço de saúde. Em seguida, realizou-se a organização, análise e interpretação dos dados com apoio da literatura do campo.

A observação e as entrevistas foram realizadas mediante utilização de roteiros previamente elaborados. Na estratégia adotada, levou-se em conta a importância de se incluir o ponto de vista das mulheres entrevistadas, ou seja, de valorizar a perspectiva de quem vive a experiência que está sendo apresentada na interação com o pesquisador. ${ }^{21}$ Este recurso foi fundamental para uma maior compreensão sobre o tema, tendo em vista a posição de nutricionista da pesquisadora principal do estudo na estrutura social, que tende a direcionar o olhar de um modo muito específico para as questões abordadas. Nesta direção, a compreensão decorrente do processo de investigação delineado a partir desta perspectiva teoria-metodológica é a base da ação educativa nas questões relativas à alimentação, o que aponta a importância da perspectiva etnográfica nas pesquisas no campo da alimentação e cultura.

A organização e a interpretação dos dados ocorreram em duas etapas. A primeira foi composta da transcrição das entrevistas, leitura e releitura do material, uma vez que havia a necessidade de 
ordenação e classificação dos dados. Esta etapa permitiu observar estruturas de relevância e ideias centrais que se destacaram no corpus. A segunda etapa correspondeu à realização de uma leitura horizontal e exaustiva dos textos, possibilitando a construção das categorias empíricas. Buscou-se estabelecer conexões entre as unidades de sentido identificadas e a literatura. Posteriormente às análises de ordenação e classificação, seguiu-se para a tarefa de agrupamento das classificações, buscando compreender e interpretar os aspectos expostos como mais relevantes e representativos nas narrativas pelo grupo. ${ }^{19}$ Adotou-se o princípio da saturação das questões abordadas na composição do estudo para o encerramento das entrevistas. ${ }^{22}$

\section{Caracterização das informantes}

A designação "camadas populares" ou "classes populares" assumida neste estudo apoia-se na vertente de tradição antropológica que designa determinados segmentos sociais em contexto urbano no Brasil como "classes trabalhadoras". ${ }^{23}$ Não corresponde, portanto, a uma definição do grupo do estudo realizada exclusivamente por critérios de classificação de renda, mas que considera um gradiente mais amplo de características, que comporta as dimensões simbólicas e culturais delimitadoras de determinados grupos sociais, sobretudo aqueles que são parte de sociedades complexas, como a contemporânea, constituídas de amplos processos como o da globalização.

As informantes possuíam idade entre 23 e 64 anos. Em relação ao diagnóstico nutricional, dezoito possuíam obesidade em seus diferentes níveis: grau I $(n=8)$, grau II $(n=5)$ e grau III $(n=5)$, estando as demais $(n=3)$ em situação de excesso de peso. Nos arranjos familiares, houve um predomínio do tipo mulher e cônjuge com filhos, sendo mais frequente a união consensual com inicio na juventude. Havia ainda duas informantes solteiras com filhos, uma viúva e uma com o marido no cárcere.

Em relação à ocupação, treze entrevistadas trabalhavam no setor formal, em atividades como limpeza e serviços gerais (6), serviços de saúde (4), cozinheira (1), auxiliar de escritório (1), técnica em enfermagem (1). Entre aquelas ligadas ao setor informal de trabalho, três exerciam serviços de limpeza em domicílios, uma era manicure e uma, catadora de material reciclável. Havia duas pensionistas do Instituto Nacional do Seguro Social (uma por tempo de contribuição; outra por viuvez) e uma desempregada. O salário destas mulheres era a única fonte de renda para uma considerável parte das famílias $(n=9)$, sendo também importante na complementação financeira das demais $(n=12)$. Quanto à escolaridade, apesar de estarem majoritariamente inseridas em ocupações com menor exigência escolar, há um predomínio de mulheres com Ensino Médio completo $(n=10)$, seguido de Ensino Fundamental $(n=7)$ e Ensino Superior $(n=3)$, completo ou incompleto. Apenas uma das informantes relatou nunca ter frequentado uma escola, apesar de não ser analfabeta. 


\section{Resultados e Discussão}

\section{Como se articulam as informações hoje disponíveis para a escolha alimentar? Quais elementos interferem nas opções cotidianas?}

A busca por um padrão alimentar considerado adequado assumiu centralidade no cotidiano das pessoas, ligando-se diretamente aos hábitos de vida e à aparência corporal. ${ }^{11,12}$ Produzida no imaginário das sociedades pós-tradicionais, a idealização da alimentação saudável guarda estreita relação com a concepção biomédica, sobre a qual o campo da nutrição se consolidou nas últimas décadas. ${ }^{18}$

Ciência, mídia e publicidade contribuem de forma especial para a atribuição de sentidos ao conceito de alimentação saudável. Se, por um lado, a produção científica que se liga à temática direciona a elaboração de diretrizes e orientações normativas sobre o que, como, quanto e quando comer; por outro, ecos deste mesmo discurso são reproduzidos em revistas especializadas sobre saúde e alimentação, programas de televisão ou redes sociais. ${ }^{24}$ Ressalta-se, nesse contexto, o quanto a internet se configurou como importante plataforma de dispersão de discursos ligados à "saúde alimentar", emergindo como espaço privilegiado na busca de informações, que, no entanto, não possuem isenção de interesse. ${ }^{25,26}$ Pela questão de alcance e possibilidade de recursos, seu uso é incentivado, inclusive, por alguns profissionais de saúde.

Eu tava olhando uma coisa na internet... eu vejo umas palestras de médico na internet (...) Ele falando que você tem que se policiar muito, pra não confundir ansiedade com fome. Né? É isso que eu não sei lidar. Tô ansiosa? Vou subir e desce escada... Não! Eu vou comer... é mais fácil né? (E 15, 29 anos, IMC 57,7 kg/ $\mathrm{m}^{2}$ ).

Ciência e o senso comum guardam estreita relação entre si. Nesse âmbito, as crenças tradicionais têm sido constantemente confrontadas ante as novas e, por vezes, confusas descobertas da ciência, o que, de certa forma, fragiliza os critérios tradicionais usados na seleção alimentar e abre espaço para o delineamento de novas práticas que conformam "modas" alimentares. ${ }^{27,28}$ Nesse sentido, as "teorias científicas" são apropriadas no cotidiano das pessoas, sendo ressignificadas por meio do senso comum, como se vê a seguir:

A farinha de linhaça, a quinoa... que isso eu tenho em casa é tipo assim: foi que eu vendo reportagem... a... farinha de linhaça pra baixar colesterol - então eu vou comprar e botar na comida, um pouquinho misturado no feijão. Que é um pouco ruim, tem gosto de óleo... (...) A quinoa: fazer de manhã o suco verde e botar junto uma colher de quinoa é bom pra num sei o quê. Eu vou assistindo a reportagem e vou prestando atenção em tudo aquilo (E3, 43 anos, IMC 37,66 kg/ $\left.\mathrm{m}^{2}\right)$. 
As questões presentes nas narrativas das entrevistadas chamam a atenção para a abrangência do acesso à informação, bem como pela variedade de discursos relacionados à escolha alimentar. Ora ligados às questões de saúde, ora à estética corporal, ora ao prazer que se liga ao comer, ora pela culpa em fazê-lo. Fischler ${ }^{29}$ denomina como 'polifonia dietética' a situação de pluralidade de informações que cercam o tema, que, em última instância, gera um conjunto confuso de saberes ao qual denominou 'cacofonia alimentar'. Esta profusão e difusão de informações que ora se convergem, ora se confrontam resultam numa situação de desorientação e incerteza perante a alimentação.

A multiplicidade de informações e apelos se espraia através da publicidade de produtos, que impulsiona a comercialização de alimentos e serviços por meio da apropriação do discurso técnico-científico, utilizando-o pra adicionar a estes uma vantagem de caráter terapêutico. ${ }^{30} \mathrm{Um}$ segmento da indústria alimentícia ainda utiliza a marca do saudável na diversificação de produtos e publicidade dos mesmos. Estas imagens e informações conjugam-se a outros elementos, tal qual o gosto, pensado na perspectiva bourdieusiana, ${ }^{31}$ fomentando a construção de sentidos sociais que orientam o comportamento diante do alimento.

"Se eu vejo que aquilo não tá surtindo efeito eu mudo pra outra coisa, não fico insistindo. Por exemplo, o que me ajudou a baixar o colesterol foi a farinha de berinjela, entendeu? (...) A quinua comprei mas não compro mais, porque acho que não évalido: pelo preço e também o outro faz o mesmo efeito (E21, 57 anos, IMC $\left.28,50 \mathrm{~kg} / \mathrm{m}^{2}\right)$.

Se, por um lado, os produtos e "fórmulas" veiculados nas mensagens se confrontam a constrangimentos financeiros próprios das camadas populares;, por outro, movem-se no imaginário social dessas mesmas mulheres como alternativas possíveis para o alcance de sucesso em relação ao emagrecimento. Prescrições alimentares realizadas por profissionais, muitas vezes confundidas e denominadas como 'práticas educativas', confundem-se com as veiculadas na mídia, associadas a um mercado de produtos comercializados com a promessa da conquista de uma boa forma, tal qual expresso por E3:

"Eu tava de férias e aí andando por Bonsucesso, a menina me deu um papelzinho. Ai foi, me convidou pra subir lá no prédio, pra conhecer... Eu disse: tô com pressa e ela não, não, mas vamos lá! Só 10 minutinhos! Eu fui. Chegando lá, ela já bateu o shake. Me perguntou o sabor que eu queria... eu queria morango, adorava morango! Ela fez de morango. Bebi. Bebi o chá. Aí ela: Ó, vem amanhã pra gente tirar medida e que num sei o que... ai mostrou lá aquele tanto de coisa. (...) Em dois meses eu perdi 7 kg. Só que é muito caro!! (...) Em fevereiro eu voltei a trabalhar e já não dava pra eu ir lá todo dia. (...) vou te vender o shake pra tu tomar em casa e te ensinar como é que faz. (...) Comprei e comecei tomar (...) caramba este negócio tá ficando difícil, porque eu tô tendo que gastar quase quinhentos reais de shake no mês!" (E3, 43 anos, IMC 37,66 kg/ $\mathrm{m}^{2}$ ).

Insegurança e desconfiança são muitas vezes acompanhadas de um sentimento de incompetência: existe uma dificuldade na apropriação de um discurso legitimado, bem intencionado, em relação 
à alimentação saudável, cujas características, no entanto, não promovem uma real aproximação daqueles para os quais ela se destina. Este é o ponto-chave daquilo que se convencionou chamar educação alimentar e/ou 'práticas educativas' em alimentação: a desqualificação dos diferentes modos de "comer". Promovida pela redução conceitual da ideia de alimentação a um nível estritamente biológico, o discurso de promoção da saúde concede espaço para um 'esvaziamento de saber' dos sujeitos.

(...) Eu vou ter que aprender muito. Tenho que aprender muito ainda. É como eu tô falando, o principal é a alimentação: aprender a se alimentar bem e com saúde, não é isso? (E1, 45 anos, IMC 37,8 kg/ $\left.\mathrm{m}^{2}\right)$.

Mas assim, até falei com meu esposo, tanto ele quanto eu somos gordinhos... vamos procurar nos educar... não só pela estética mas pela saúde também (E17, 28 anos, IMC $\left.30 \mathrm{~kg} / \mathrm{m}^{2}\right)$.

Em direção similar à lógica do risco ${ }^{32}$ que rege o discurso da saúde e na qual se assentam historicamente as premissas das práticas educativas, as ações de educação alimentar exercem pressão sobre a carga de responsabilidade individual, uma vez que partem do princípio de que as pessoas deveriam usar da racionalidade para efetuar as melhores escolhas:

A psicóloga me falou isso: o dia que você botar na sua cabȩ̧a que a comida não é uma fonte de prazer, é só uma necessidade pra te manter viva, vai te ajudar uns $90 \%$. Mas é difícil pensar assim! Ela falou assim pra mim: Quando você tiver vontade de comer... vai ler um livro! Eu vou é comer o livoro! (E15, 29 anos, IMC 57,7 kg/m²).

Esta situação amplifica a culpa atribuída àqueles que não conseguem fazer a escolha considerada mais adequada no âmbito dos saberes científicos.

Eu me culpo... me culpo de querer entender certas coisas, que eu não entendo. Eu não estudei... minha mente não é aberta pra certas coisas que eu não estudei... Porque as vezes você vai falar assim: não come este torresmo não, isso faz mal pra você. Não coma não... Coma uma maçã. Eu vou falar com você: mas eu tô com vontade de comer este torresmo, então eu vou comer o torresmo. Porque se eu não emagreço e se eu tô com vontade de comer o torresmo, eu vou comer o torresmo. Eu penso muito [...] (E13, 54 anos, IMC 66,83 kg/ $\left.\mathrm{m}^{2}\right)$.

(...) eu quero que o comer seja uma coisa que... Que não me preocupe. Se vou almoçar: eu quero que seja uma coisa banal, igual escovar o dente, igual pentear o cabelo. Sem sentir culpa (E15, 29 anos, IMC 57,7 kg/ $\left.\mathrm{m}^{2}\right)$.

A culpabilização se dá a partir da existência idealizada de um sujeito autônomo, capaz de estabelecer relações de custo/benefício em suas ações diárias. ${ }^{33}$ Porém, a margem da "livre escolha" se conforma de acordo com possibilidades e constrangimentos que se configuram em uma rede de processos, que diferenciam as alternativas reais dos indivíduos e dos grupos sociais. Acontece que a racionalidade efetivamente exercida nem sempre corresponde àquela preconizada por 
estudos de risco, que não cedem lugar à compreensão dos significados que se ligam à alimentação enquanto prática socialmente compartilhada conectada à sociabilidade, ao prazer e às condições objetivas de vida.

Existem dimensões relacionadas às questões mais amplas de acesso e recursos financeiros no que tange ao consumo de alimentos. Um exemplo marcante da ressignificação do discurso ligado à saúde alimentar foi apresentado por uma das informantes, que, ao justificar a falta de pão em seu café da manhã, vale-se da presença de glúten a partir da perspectiva glúten free, tão em voga recentemente, em vez de expressar a vivência de uma limitação financeira:

“(...) Às vezes quando não tem pão eu tomo café puro. Até que é bom, porque dizem que pão tem glúten e glúten faz mal” (E12, 31 anos, IMC 32,20 kg/ $\left.\mathrm{m}^{2}\right)$.

Discursos como o da educação nutricional, usualmente realizado no âmbito da assistência e promoção da saúde, têm o poder e a autoridade de designar suas próprias práticas sociais como legítimas e, portanto, saudáveis. Ao não se atentar para os contextos socioculturais e econômicos mais amplos de produção, por exemplo, do excesso de peso, este tipo de ação assume, por vezes, uma feição moralista, produzindo culpa e sofrimento em grupos de indivíduos que não conseguem se adaptar ao modelo prescrito. A identificação das práticas alimentares de grupos 'marginalizados' como insalubres tem, por vezes, justificado e mantido determinadas desigualdades na própria assistência:

"Ele [o médico] orienta várias coisas. Primeiro é a dieta, essa aí deixa de lado" (E2, 47 anos, IMC 55,55 kg/m²).

Ao não reconhecer "o outro", cria-se um conhecimento aparentemente objetivo, que, no entanto, limita a compreensão das condições históricas e sociais que distinguem os grupos sociais entre si, sustentando dinâmicas de poder desiguais e obscurecendo o fato de que o que é considerado legítimo e saudável pode, inclusive, ser temporalmente relativo.

A lógica do conceito de educação alimentar baseada na perspectiva de valor nutricional e de racionalidade das escolhas permeou consideráveis ações de enfrentamento dos problemas alimentares brasileiros, se não a totalidade delas, tanto no âmbito coletivo quanto no individual. ${ }^{2,3,34}$ Uma análise reflexiva feita por Lima et al. ${ }^{34}$ sobre a perspectiva histórica relacionada à educação nutricional entre os anos 1980 e 1998 apresenta o deslocamento conceitual que marca a transição da ideia de uma população em situação de "ignorância alimentar" para a representação social do nutricionista como educador no âmbito de sua formação e prática profissional. Entretanto, mesmo como prática incorporada à assistência em saúde, bem como em políticas públicas, as estratégias de educação alimentar vêm apresentando avanços limitados. ${ }^{16}$ Esta situação cedeu espaço, no âmbito 
das ações de enfrentamento ao excesso peso, à noção de 'reeducação' como estratégia que propõe a retomada do prazer na alimentação via autocontrole individual. Esta idealização está presente tanto na prática profissional quanto no imaginário social. ${ }^{35}$

A complexidade da questão, que será discutida com mais detalhes em seguida, está nos limites à autonomia em relação às diferentes possibilidades de escolha alimentar. Num contexto de transformação das regras sociais que se ligam ao "comer" e de multiplicidade de informações e conselhos dirigidos aos sujeitos, bem como de limites financeiros vivenciados por determinados grupos sociais, as escolhas são muito mais complexas:

“(...) Tão falando que o suco tá dando câncer [suco em pó]. Como é que eu vou fazer? Tem que ser da fruta então... da fruta é melhor. Mas a fruta tá cara. Tem que ser do pozinho mesmo” (E12, 31 anos, IMC 32,20 kg/m²).

\section{Reeducação Alimentar: proposta alternativa às dietas?}

Apesar de pobremente contextualizado na literatura científica produzida no campo da alimentação e nutrição, o conceito de reeducação surge a partir da década de 1990 nos discursos oriundos das camadas médias e altas, como uma experiência ligada à saúde alimentar. ${ }^{36,37}$ Idealizase que um indivíduo 'reeducado' não terá mais problemas com o peso, uma vez que ele está ciente do que se pode e não se pode fazer.

Intimamente articulado à noção de estilo de vida, o conceito de reeducação nutricional é central no discurso da promoção da saúde alimentar vigente nos dias atuais. Ele emerge também nas camadas populares, sendo evidenciado pelas narrativas das informantes como algo que pode atender aos anseios individuais, promovendo emagrecimento definitivo. Em sua essência, a proposta se contrapõe à rigidez das dietas por meio da retomada do prazer de se comer:

(...) Eu botei na minha mente que não é fazer dieta, que dieta assusta! Fazer regime... ai meu Deus! Eu tô me reeducando! Menos traumático. Imagina tu passar a vida inteira: dieta! dieta! dieta! A vida inteira ouvindo a mesma coisa. Cansa! (E15, 29 anos, IMC $\left.57,7 \mathrm{~kg} / \mathrm{m}^{2}\right)$.

Caracterizado pelas noções de flexibilidade e inovação, a reeducação apresenta-se como uma estratégia de construção do gosto a partir de uma ressignificação do comer, como se a retomada do prazer de em fazê-lo pudesse se alinhar ao discurso legitimado pela ciência da nutrição. A ideia de flexibilidade substitui comandos que apontam proibição como "cortar" ou "não pode comer", tal qual exposto por E5:

Não eu... vamos dizer... comer... é... (...) como eu tô te falando, eu me reeduquei dia de semana. Não tomo mais refrigerante. Mas se eu tiver que comer lasanha, eu como um pedaço: tudo moderado. Né com gula não, nem desespero. É moderado (E5, 28 anos, IMC $\left.25,1 \mathrm{~kg} / \mathrm{m}^{2}\right)$. 
O indivíduo chamado a participar da construção cotidiana da sua alimentação por meio da aprendizagem do que e quanto comer, do como e quando comer, exercitando o controle dos desejos e prazeres ligados à alimentação. Moderação é um termo associado ao discurso de saúde presente na proposta de reeducação. Nesse sentido, uma "condição saudável” de existência implicaria uma expressão positivada de sua identidade, sendo a obesidade, supostamente, resultado de más escolhas. Entretanto, esta não é uma tarefa fácil, existem particularidades nas possibilidades de acesso e peculiaridades nas formas de consumo entre os diferentes grupos sociais para os quais o mercado se adapta. Grupos sociais economicamente desfavorecidos são mais constrangidos ao consumo de alimentos baratos, práticos e palatáveis, que, em última instância, conformam como um gosto de classe. ${ }^{31}$

Pelo que eu vejo na televisão, olha que você tem que comer comida saudável, salada, aquilo outro... Agora botô queijo no meio... [suspira]. E eu sei que é ruim. Eu como com pão, com macarrão, com miojo... Vai dizer que isso é bom? Claro que não, eu não sou burra. Que uma comida que fica pronta com 3 minutos, vai dizer que ela é saudável? Ela não é! Não é... De jeito nenhum. (...) E a gente sabe que se alimenta mal, sabe que se alimenta mal, mas... (E1, 45 anos, IMC 37,8 kg/m²).

As expectativas positivas associadas à reeducação alimentar expressam os sentidos negativos atribuídos à dieta dentro do grupo. Questões ligadas ao custo de sua manutenção, ao tempo necessário para o preparo e consumo, bem como à restrição alimentar, estão presentes nas narrativas.

Porque não é fácil hoje manter uma dieta. Não é fácil... É muito fácil chegar e falar... ah... Porque eu vou comer uma laranja, vou comer uma banana, vou comer uma maçã. Primeiro que no meu caso, eu não tenho tempo (E1, 45 anos, IMC 37,8 kg/m²).

Eu até pensei: segunda feira eu vou fazer uma dieta. Vou fazer uma dieta! Só que eu não consigo (E9, 51 anos, IMC $\left.35,58 \mathrm{~kg} / \mathrm{m}^{2}\right)$.

Nesse sentido, a reeducação apresenta-se diferente da 'dieta' pela proposição de mudanças permanentes nas práticas alimentares, sendo o autocontrole um dos aspectos centrais do processo:

Diminuir carboidrato, eu consegui. Mas no outro eu fracassei, que era... era... ser mais ativo. Eram duas metas. Então eu continuei com as duas, porque na outra eu fracassei. Esse negócio de ser mais ativo é muito difícil, muito difícil. Eu sou muito sedentária. Essa pra mim é uma das mais difíceis, até o final. (...) Eu tenho que me reeducar, eu estou sendo alfabetizada na área de alimentação (E15, 29 anos, IMC 57,7 kg/ $\left./ \mathrm{m}^{2}\right)$.

Percebe-se através das narrativas que a reeducação repete, em boa medida, a mesma estratégia da educação nutricional: recomendações de autocuidado ligadas a uma prescrição normativa, 
quase sempre distanciada da realidade cultural e financeira das informantes. Situação que não se sustenta por muito tempo no cotidiano das pessoas.

[...] com dieta tem que comprar o filezinho todo dia, que é caro... as verduras, que tem que comprar todo dia, que tá muito caro; e assim, outras coisas mais. Arroz integral, pão integral... pãa integral. E assim, acaba que fica muito difícil porque hoje você começa uma coisa, mas amanhã tu não tem mais dinheiro. Aí tu começa a furar... fica cheio de buraco. E tu acaba abrindo mão (E2, 47 anos, IMC 55,55 kg/ $\left.\mathrm{m}^{2}\right)$.

A possibilidade imaginária de comer de tudo sem passar fome, apesar de sedutora, implica a realização cotidiana de escolhas. Entretanto, o exercício do autocontrole amplifica responsabilidade e, consequentemente, a culpa, situação expressa por uma informante:

“(...) Mas é porque eu não consegui fazer uma reeducação correta... é um mau exemplo. Mas um dia eu vou conseguir fazer uma reeducação correta!” (E17, 28 anos, IMC $30 \mathrm{~kg} / \mathrm{m}^{2}$ ).

A individualização da escolha também promove um distanciamento do âmbito coletivo, possibilitando uma maior desestruturação da construção sociocultural que se liga às práticas alimentares, abrindo espaço para o delineamento de novas regras que podem trazer consigo algum grau de gastro-anomia. ${ }^{38}$ Essa experiência requer um contínuo exercício de disciplina e, apesar de aparentemente ampliar o poder de decisão do indivíduo, na verdade reforça sua responsabilidade, bem como sua ansiedade. Isso amplia a procura por "milagres nutricionais", fomentando demandas de consumo.

Como vimos, programas de emagrecimento que reproduzem um discurso técnico-científico são reelaborados dentro de uma lógica publicitária que oferece uma gama de alimentos e/ou produtos lançados e substituídos. ${ }^{35}$ Esta situação alimenta um mercado que, além de ofertar ultraprocessados como alternativa pretensamente saudável, também oferece possibilidades de "cura" por meio da comercialização não só de produtos, mas de serviços de maior ou pior qualidade, dependendo do público aos quais se destinam. A narrativa de E15 expressa a maior exposição de determinados grupos ao consumo de serviços e atendimentos em saúde de procedência duvidosa:

Fui parar num médico lá em Caxias, que está até preso (...). Ai ele passou uma fórmula pra mim, cara à bessa! Quase $R \$ 200,00$. Eu tinha até visão com aquilo ali. (...) Não tinha fome, não comia... Depois tinha um pozinho que botava embaixo da língua, aquilo me deixava leve... Mas tudo eu mandei fazer na farmácia de manipulação: tudo ótimo! (...) quando eu parei de tomar engordei o dobro (E15, 29 anos, IMC 57,7 kg/ $\left./ \mathrm{m}^{2}\right)$.

A ampliação do mercado no contexto da reeducação está também ligada ao uso de tecnologia. No campo da nutrição há uma diversidade de aplicativos para celulares que permitem desde a contagem de calorias, manutenção de diários alimentares, monitoramento do gasto energético 
até o controle da ingestão hídrica, sendo este último um recurso usado entre as informantes. Num contexto de reaprendizagem, as novas tecnologias são incorporadas no dia a dia como "importantes ferramentas" no processo de controle de si, instrumentalizadas para fomentar a promoção da "boa saúde". ${ }^{39,40}$

Ah... tem um aplicativo que ajuda a beber água, (...) pede a altura, quantos quilos e a idade para calcular quanto de água precisa beber e tal... botei tudinho: aí veio pra mim beber três 3,10 litros de água, não veio três certinho não... Mas porque 10 mililitros? [risos] Pelo peso né? Tá. Aí eu botei o aplicativo pra alarmar de $2 \mathrm{em}$ 2 horas... (...) Se eu não fosse lá e apertasse, daí a pouco vinha uma mensagem: você esqueceu de tomar água. Ai eu comecei... um copo (...) Separei um copo de $300 \mathrm{~mL}$, pra mim beber três litros por dia tinha que beber dez [copos]. Cara, se é difícil pra tomar um, imagine dez. De duas em duas horas, eu comecei... Primeiro dia, aquilo chato, tá bebendo água e indo no banheiro fazer xixi... Quanto foi depois, eu aumentei o copo de água no aplicativo para de $500 \mathrm{~mL}$, porque eu sei que se for de $500 \mathrm{ml}$ eu vou 6 copos no dia [...] Pronto agora eu já bebo água... tirei o aplicativo. Agora já bebo agua direitinho (E3, 43 anos, IMC 37,66 kg/ $/ \mathrm{m}^{2}$ ).

A proposta de "educar de novo" ou "reeducar" como a abertura de um caminho para uma nova ordem alimentar está, em grande medida, fadada ao insucesso ao não romper com um discurso normativo e impositivo, como já apontado anteriormente. É preciso compreender que além da necessidade biológica inerente à manutenção da vida, "comemos" de acordo com uma organização social e de acordo com uma determinada forma de produzir e distribuir alimentos, "comemos" de acordo com nossos grupos e classes de pertencimento. ${ }^{4}$ Ao não se considerar um debate verdadeiro em torno das dimensões que fomentam a atual pandemia de obesidade, que não se restringem à informação nutricional, a perspectiva de reeducação evidencia a repetição de um modelo que limita a construção de práticas alimentares que se sustentem no cotidiano dos grupos sociais. Assim como no caso de prescrições dietéticas que negam práticas e vivências alimentares ligadas à cultura dos grupos, há pequena chance de sustentação de propostas de reeducação que tentem calar não somente as dimensões sociais e afetivas, mas também deixem de considerar determinadas imposições econômicas e de mercado que se inscrevem no "comer".

\section{Considerações finais}

Este artigo se propôs uma reflexão sobre os discursos normativos e práticas alimentares relacionados à perda de peso em mulheres de camadas populares a partir da ideia de reeducação alimentar que emergiu das narrativas. Com base nas questões apresentadas, observa-se que o discurso biomédico normatiza condutas prescritivas ligadas à alimentação e ao corpo, desconsiderando, na maioria das vezes, a conjuntura social dos diferentes grupos, principalmente aqueles em vulnerabilidade financeira. Estas recomendações se distanciam das possibilidades concretas de realização, ampliando ansiedades e sofrimento daquelas que não conseguem se 
adaptar ao modelo prescritivo. Apesar de o conceito de reeducação emergir como alternativa de mudança entre as entrevistadas, ele acaba apresentando-se tão limitador quanto a prescrição dietética convencional, porque também se baseia numa perspectiva normativa de saúde alimentar. Nesse sentido, qual seria o papel "educativo" do profissional da nutrição nesta seara? Não há resposta simples para esta questão, o que se evidencia, no entanto, é a necessidade urgente de ampliação nas formas de aproximação e enfrentamento mais compreensivos do excesso de peso, a partir de abordagens que respeitem não somente as condições materiais, mas também questões que se conectam à cultura e à identidade dos grupos sociais. Sem análise e compreensão mais aprofundada sobre as diferentes dimensões que se ligam à pandemia, dificilmente o problema da obesidade terá reversão.

\section{Colaboradores}

TC Oliveira, D Czeresnia e EP Vargas trabalharam em todas as etapas, desde a concepção do estudo até a revisão da versão final do artigo.

Conflito de interesses: Os autores declaram não haver conflito de interesses.

\section{Referências}

1. Boog MCF. Educação nutricional: passado, presente, futuro. Rev Nutr. 1997; 10:5-19.

2. Lima ES. Gênese e constituição da educação alimentar: a instauração da norma. História, Ciências, Saúde - Manguinhos 1998; 1:57-83.

3. Santos LAS. Educação alimentar e nutricional no contexto da promoção de práticas alimentares saudáveis. Rev Nutr. 2005; 18(5):681-692.

4. Canesqui AM, Garcia RWD. organizadores. Antropologia e nutrição: um diálogo possível. Rio de Janeiro: Editora FIOCRUZ; 2005. 306 p. Antropologia e Saúde.

5. Ayres JRCM. Epidemiologia, promoção da saúde e o paradoxo do risco. Rev Bras Epidemiol. 2002; 5(Supl.1):S28-S42.

6. Azevedo E. Reflexões sobre riscos e o papel da ciência na construção do conceito de alimentação saudável. Rev Nutr. 2008; 21(6):717-723.

7. Duncan BB, Chor D, Aquino EML, Bensenor IM, Mill JG, Schmidt MI, et al. Doenças crônicas não transmissíveis no Brasil: prioridade para enfrentamento e investigação. Rev Saúde Pública 2012; 46(Supl.1):126-134.

8. World Health Organization. Obesity: preventing and managing the global epidemic: report of a WHO consultation. Geneva: WHO; 2000. WHO technical report series; 894. 
9. Bosi MLM. Profissionalização e conhecimento: a nutrição em questão. São Paulo: Hucitec; 1996. 205 p.

10. Camargo Jr KR. As armadilhas da concepção positiva de saúde. Physis 2007; 17(1):63-76.

11. Beck U, Giddens A, Lash S. Modernização reflexiva. São Paulo: Editora Unesp; 1997.

12. Giddens A. Identidade e modernidade. Rio de Janeiro: Jorge Zahar; 2003.

13. Castiel LD, Ferreira MS, Moraes DR. Os riscos e a promoção do autocontrole na saúde alimentar: moralismo, biopolítica e crítica parresiasta. Ciênc Saúde Coletiva 2014; 19(5):1523-1532.

14. Santos LAS. Os programas de emagrecimento na Internet: um estudo exploratório. Physis 2007; 17(2):353-372.

15. Farias SJSS, Fortes RC, Fazzio DMG. Análise da composição nutricional de dietas da moda divulgadas por revistas não científicas. Nutrire 2014; 39(2):196-202.

16. Instituto Brasileiro de Geografia e Estatística. Pesquisa nacional de saúde: 2013: ciclos de vida: Brasil e grandes regiões. Rio de Janeiro: IBGE; 2015. 92 p. Disponível em: http://biblioteca.ibge.gov.br/ visualizacao/livros/liv94522.pdf

17. Castro IRR. Desafios e perspectivas para a promoção da alimentação adequada e saudável no Brasil. Cad Saúde Pública 2015; 31(1):07-09.

18. Viana MR, Neves AS, Camargo Junior KR, Prado SD, Mendonça ALO. A racionalidade nutricional e sua influência na medicalização da comida no Brasil. Ciênc Saúde Coletiva 2017; 22(2):447-56.

19. Peirano M. Etnografia não é método. Horiz Antrop. 2014; 20(42):377-391.

20. Minayo MCDS, Guerriero ICZ. Reflexividade como éthos da pesquisa qualitativa. Ciênc Saúde Coletiva 2014; 19(4):1103-1112.

21. Fraser MTD, Gondim SMG. Da fala do outro ao texto negociado: discussões sobre a entrevista na pesquisa qualitativa. Paidéia 2004; 14(28):139-152.

22. Fontanella BJB, Luchesi BM, Saidel MGB, Ricas J, Turato ER, Melo DG. Amostragem em pesquisas qualitativas: proposta de procedimentos para constatar saturação teórica. Cad Saúde Pública 2011; 27(2):389-394.

23. Duarte LFD. Da vida nervosa nas classes trabalhadoras urbanas. Rio de Janeiro: Zahar; 1988.

24. Andrade A, Bosi MLM. Mídia e subjetividade: impacto no comportamento alimentar feminino. Rev Nutr. 2003; 16(1):117-125.

25. Moretti FA, Oliveira VE, Silva EMK. Acesso a informações de saúde na internet: uma questão de saúde pública? Rev Assoc Med Bras. 2012; 58(6):650-658.

26. Teo CRPA. Discursos e a construção do senso comum sobre alimentação a partir de uma revista feminina. Saúde Soc. 2010; 19(2):333-346.

27. Paty M. A ciência e as idas e voltas do senso comum. Scientiae Studia 2003; 1(1):9-26.

28. Oliveira TC, Czeresnia D, Vargas EP, Barros DC. Concepções sobre práticas alimentares em mulheres de camadas populares no Rio de Janeiro: transformações e ressignificações. Interface 2018; 22(66): (no prelo). 
29. Fischler C. Obeso benigno e obeso maligno. In: Sat'Anna D, organizadores. Políticas do corpo. São Paulo: Estação Liberdade; 1995. p. 69-80.

30. Gracia-Arnaiz M. Comer bien, comer mal: la medicalización del comportamento alimentario. Salud Pública de México 2007; 49:236-242.

31. Bourdieu P. Gosto de classe e estilo de vida. In: Ortiz R. Pierre Bourdieu. São Paulo: Ática; 1983. p. 82-121.

32. Czeresnia D. Ciência, técnica e cultura: relações entre risco e práticas de saúde. Cad Saúde Pública 2004; 20(2):447-455.

33. Bagrichevsky M, Castiel LD, Vasconcellos-Silva PR, Estevão A. Discursos sobre comportamento de risco à saúde e a moralização da vida cotidiana. Ciênc Saúde Coletiva 2010; 15(Supl.1):1699-1708.

34. Lima ES, Oliveira CS, Gomes MCR. Educação nutricional: da ignorância alimentar à representação social na pós-graduação do Rio de Janeiro (1980-98). História, Ciências, Saúde - Manguinhos 2003; 10(2):603-35.

35. Santos LAS. Da dieta à reeducação alimentar: algumas notas sobre o comer contemporâneo a partir dos programas de emagrecimento na Internet. Physis 2010; 20(2):459-474.

36. Boog MCF. Educação nutricional em serviços públicos de saúde. Cad Saúde Pública 1999; 15(Supl.2):S139-S147.

37. Brienza AM, Mishima SM, Frederico P, Clápis MJ. Grupo de reeducação alimentar: uma experiência holística em saúde na perspectiva familiar. Rev Bras Enferm. 2002; 55(6):697-700.

38. Fischler C. Gastro-nomie et gastro-anomie. Communications 1979; 31(1):189-210.

39. Tonkin E, Brimblecombe J, Wycherley TP. Characteristics of smartphone applications for nutrition improvement in community settings: a scoping review. Adv Nutr. 2017; 8(2):308-322.

40. Bert F, Giacometti M, Gualano MR, Siliquini R. Smartphones and health promotion: a review of the evidence. J Med Syst. 2014; 38(1):9995. 